\title{
Comunidade do Faraó: Práticas Camponesas na Área de Influência do Complexo Petroquímico do Rio de Janeiro (COMPERJ).
}

Communauté du Pharaon: pratiques paysannes dans la zone d'influence du complexe pétrochimique de Rio de Janeiro (COMPERJ).

Comunidad del Faraón: Prácticas Campesinas en el Área de Influencia del

Complejo Petroquímico de Río de Janeiro (COMPERJ).

Pharaoh Community: Peasant Practices in the Area of Influence of the Rio de Janeiro Petrochemical Complex (COMPERJ).

\section{Bruno Milan Carneiro de Albuquerque e Jacob Binsztok}

\section{(2) OpenEdition}

\section{Journals}

Edição electrónica

URL: http://journals.openedition.org/espacoeconomia/5353

DOI: $10.4000 /$ espacoeconomia.5353

ISSN: 2317-7837

\section{Editora}

Núcleo de Pesquisa Espaço \& Economia

Refêrencia eletrónica

Bruno Milan Carneiro de Albuquerque e Jacob Binsztok, « Comunidade do Faraó: Práticas

Camponesas na Área de Influência do Complexo Petroquímico do Rio de Janeiro (COMPERJ). »,

Espaço e Economia [Online], 14 | 2019, posto online no dia 10 agosto 2019, consultado o 06 setembro 2019. URL : http://journals.openedition.org/espacoeconomia/5353 ; DOI : 10.4000/ espacoeconomia.5353

Este documento foi criado de forma automática no dia 6 Setembro 2019.

(C) NUPEE 


\title{
Comunidade do Faraó: Práticas Camponesas na Área de Influência do Complexo Petroquímico do Rio de Janeiro (COMPERJ).
}

\author{
Communauté du Pharaon: pratiques paysannes dans la zone d'influence du \\ complexe pétrochimique de Rio de Janeiro (COMPERJ). \\ Comunidad del Faraón: Prácticas Campesinas en el Área de Influencia del \\ Complejo Petroquímico de Río de Janeiro (COMPERJ). \\ Pharaoh Community: Peasant Practices in the Area of Influence of the Rio de \\ Janeiro Petrochemical Complex (COMPERJ).
}

Bruno Milan Carneiro de Albuquerque e Jacob Binsztok

\section{Introdução}

1 Na última década o Estado do Rio de Janeiro, foi palco de implantação de vários empreendimentos de orientação desenvolvimentista, de cunho industrial, em várias regiões do território fluminense, que ocorreram em diferentes intensidades e intervenções realizadas a partir de 2006, de significativa amplitude social e ambiental. Essas iniciativas foram fomentadas no âmbito do Programa de Aceleração do Crescimento (PAC) do Governo Federal, lançado com a finalidade de expandir a economia nacional pela via estatal estabelecendo um contraponto com as políticas neoliberais adotadas pelos governos anteriores,que elegeram setores privados nacionais e internacionais como atores básicos para liderar o desenvolvimento econômico e social do país.

2 Algumas dessas iniciativas foram inseridas na lógica da expansão do setor de petróleo e gás, tais como: Articulação do Pólo Petroquímico com a Refinaria Duque de Caxias (REDUC), Arco Metropolitano do Rio de Janeiro, Exploração e Produção do Petróleo do Pré-Sal, Polo Siderúrgico em Queimados e o Porto de Sepetiba em Itaguaí. Estes projetos 
foram em sua maioria implantados na Baixada Fluminense e no Leste Metropolitano, com o pretexto de reforçar uma vocação industrial e logística que historicamente se delineou nestas áreas do estado do Rio de Janeiro.

3 Esta historicidade industrial da região da Baixada Fluminense influenciou estes projetos desenvolvimentistas, que apresentaram uma maior ou menor correlação com o COMPERJ (Imagem 1), que, embora instalado em Itaboraí, município externo a Baixada Fluminense, completa o circuito produtivo de petróleo e gás alicerçando a economia e contraditoriamente apontado por setores empresariais como um dos responsáveis pela grave crise econômica e social vivenciada pelo estado.

4 Neste contexto, observamos que a comunidade tradicional do Faraó, localizada no município de Cachoeiras de Macacu, situado a $22^{\circ} 27^{\prime} 45^{\prime \prime}$ de latitude sul e $42^{\circ} 39^{\prime} 11^{\prime \prime}$ de longitude oeste, com área territorial de $956 \mathrm{~km}^{2}$, distante $75 \mathrm{~km}$ da cidade do Rio de Janeiro, com uma população em 2019, de 60 mil habitantes, com 86\% concentrados na área urbana e $14 \%$ no campo, constitui-se em uma relevante diferenciação socioespacial na distribuição de sua população em relação aos demais núcleos do Leste Metropolitano, como Itaboraí e São Gonçalo considerados pelos IBGE, como totalmente urbanizados, embora esse processo de urbanização tenha ocorrido de forma acelerada e desordenada estando fortemente concentrado ao longo de rodovias federais e estaduais.

Imagem 1, mapa da Área de influência do direta do COMPERJ.

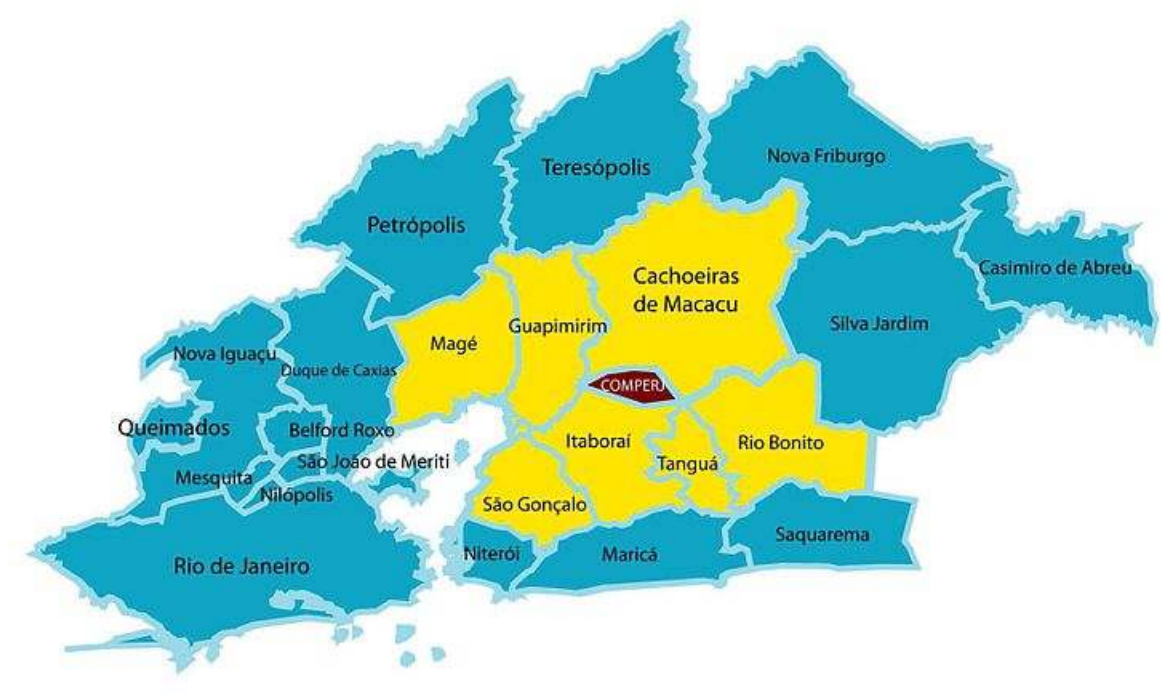

Fonte: Flávia Almeida Costa Barros, F.A.C. et al, 2011, disponivel em https://commons.wikimedia.org/ wiki/File:Mapa_comperj.jpg, acessado em 29/04/2019

5 O clima é caracterizado como tropical úmido, com amplitude térmica variando entre $13^{\circ} \mathrm{C}$ e $35^{\circ} \mathrm{C}$, não se constituindo em obstáculo para a presença de uma policultura camponesa, formada pelos cultivos de inhame, aipim, abobrinha, abóbora, berinjela, quiabo, milho, jiló, ocupando as várzeas e com a banana predominando nas encostas.

6 O município possui $40 \%$ de sua área total protegida pelas Unidades de Conservação como o Parque Estadual dos Três Picos, a Estação Ecológica do Paraíso, da Área de Proteção Ambiental do Macacu e ainda pelo Corredor Ecológico Sambê-Santa Fé, cobertas pela 
Floresta Ombrófila Densa, que se encontra muito fragmentada, caracterizada como mata sempre verde, cujo dossel é de até 50 metros e com árvores emergentes atingindo até 40 metros de altura. Embora o município tenha sido incluído na Região Metropolitana do Rio de Janeiro, apresenta conexões econômicas, sociais e ambientais com outros municípios da Baixada Fluminense como Guapimirim e Magé, limítrofes e inseridos na área de influência do COMPERJ (Imagem 1).

$7 \mathrm{Na}$ comunidade, observamos os impactos socioambientais enfrentados pela sua população, localizada no distrito de Japuíba, na Microbacia Hidrográfica do Faraó, no entorno do Parque Ecológico dos Três Picos, fazendo parte da Bacia Hidrográfica do Guapi-Macacu. A Microbacia Hidrográfica do Faraó (Imagens 2, 3 e 4) é caracterizada como contribuinte relevante da Bacia Hidrográfica do Guapi-Macacu, sendo fundamental para o abastecimento de água de importantes centros urbanos fluminenses, como Niterói, São Gonçalo e Itaboraí, sob a gestão das empresas CEDAE e Águas de Niterói. Está inserida na Bacia da Baía de Guanabara, que apresenta no seu entorno os municípios da Região Metropolitana, Leste Fluminense, Baixada Fluminense e Serrana do estado do Rio de Janeiro.

Imagem 2, Mapa de Bacias hidrográficas dos rios Guapi-Macacu e Caceribu no contexto das bacias hidrográficas contribuintes da baía de Guanabara.

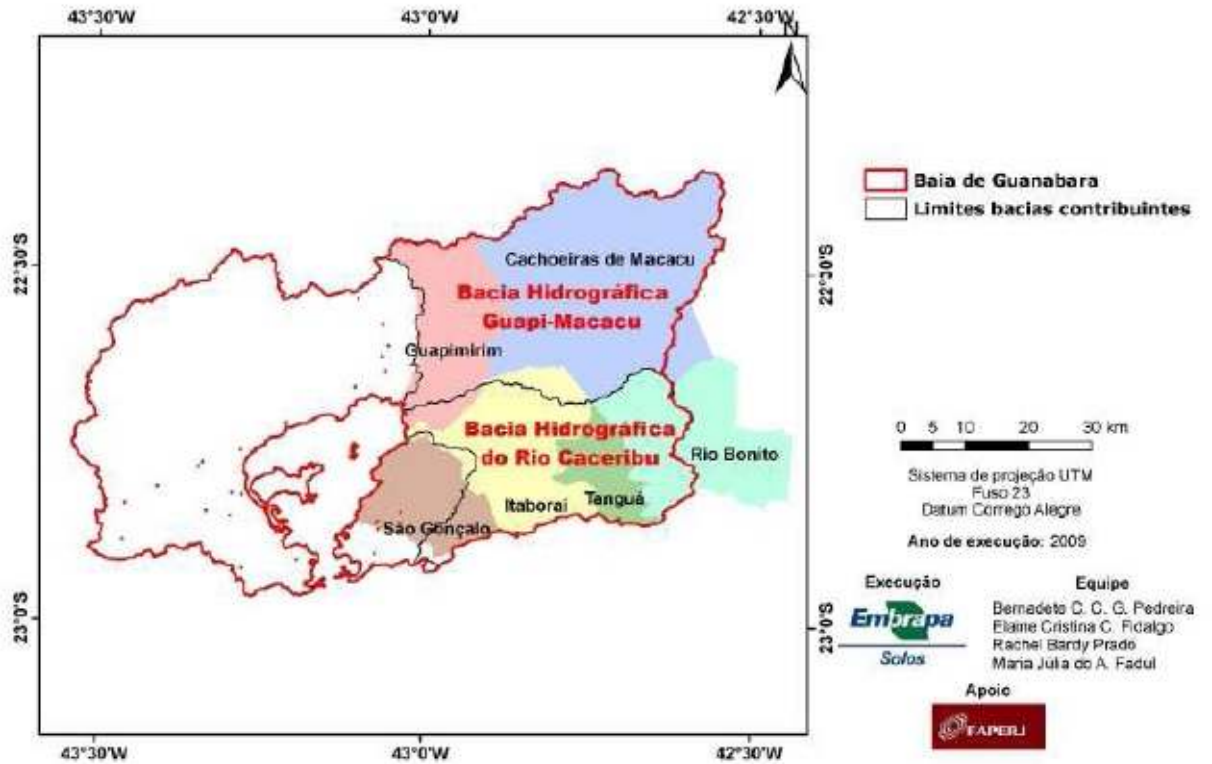

Fonte: (WILKINSON et al, 2012, p.81)

8 A comunidade do Faraó é assim chamada por estar localizada ás margens do rio do mesmo nome, que, também é conhecido como rio Batatal, sendo atingida pelo processo de reestruturação espacial promovida pela construção do COMPERJ (Imagem 1), agravada pela paralisação das obras em 2015. Os obstáculos e entraves na construção do referido complexo industrial acabaram inviabilizando uma série de pequenos empreendimentos locais, liberando significativo contingente da força de trabalho utilizada direta e indiretamente nas atividades de apoio ao empreendimento, principalmente nos municípios de Itaboraí e São Gonçalo pertencentes ao Leste Fluminense e inseridos na Região Metropolitana do Rio de Janeiro. 


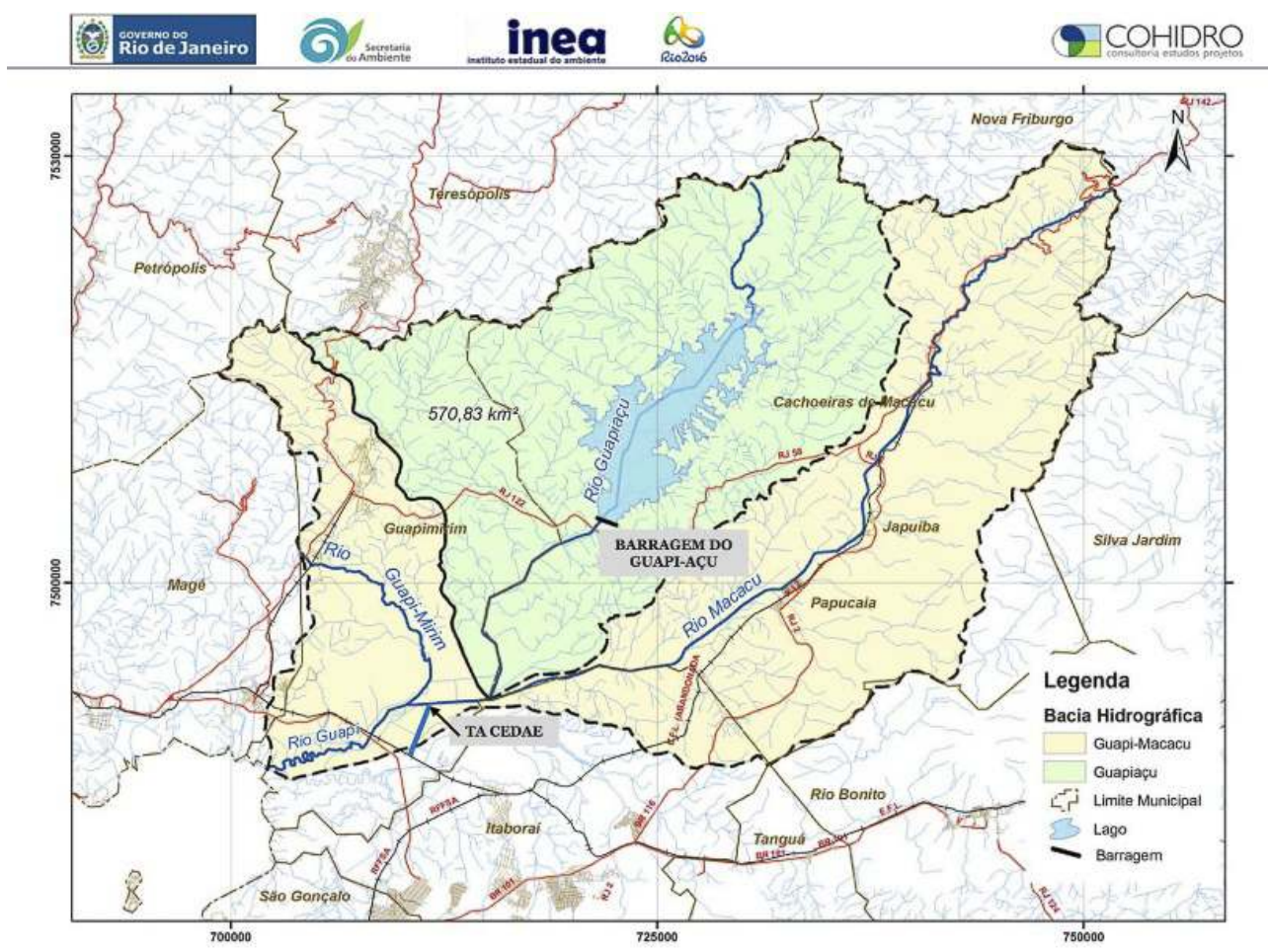

Fonte: disponível em https://www.oeco.org.br/reportagens/28985-barragem-guapiacu-entre-odialogo-e-tratoraco/ acessado em 29/04/2019.

Assim, descrevemos, conforme Martins (MARTINS, 2016, p.15), sobre a Comunidade do Faraó: “(...) ocupa uma área de 3.150 ha, com aproximadamente 136 famílias, cujas propriedades têm área inferior a 20 ha e apenas duas têm mais que 50 ha.". Essa população teve o cotidiano alterado e a sua permanência em risco, em função de problemas sociais, econômicos e ambientais. A principal atividade econômica da comunidade é o plantio tradicional da banana, que abastece os mercados da Região Metropolitana, com os agricultores em sua maioria familiares se organizando em uma cooperativa local, denominada Associação dos Lavradores e Amigos do Faraó (ALAF), que possui problemas em relação a comercialização do produto na CEASA/RJ, em função de dificuldades para o perfeito acondicionamento dos frutos nas caixas. E como afirma Cavalin e Monteiro (CAVALIN \& MONTEIRO, 2012):

O município vem se mantendo como um dos cinco maiores produtores de banana do estado do Rio de Janeiro, com uma área média colhida de aproximadamente 3 mil hectares/ano nos últimos 20 anos com uma produção média equivalente a 5 mil toneladas/ano. Ainda hoje, a região do Faraó, localizada na microbacia do rio Batatal, no $2^{\circ}$ distrito do município, se mantém como uma das principais responsáveis pela produção de banana (Musa spp.) no Estado do Rio de Janeiro. (CAVALIN \& MONTEIRO, 2012) 


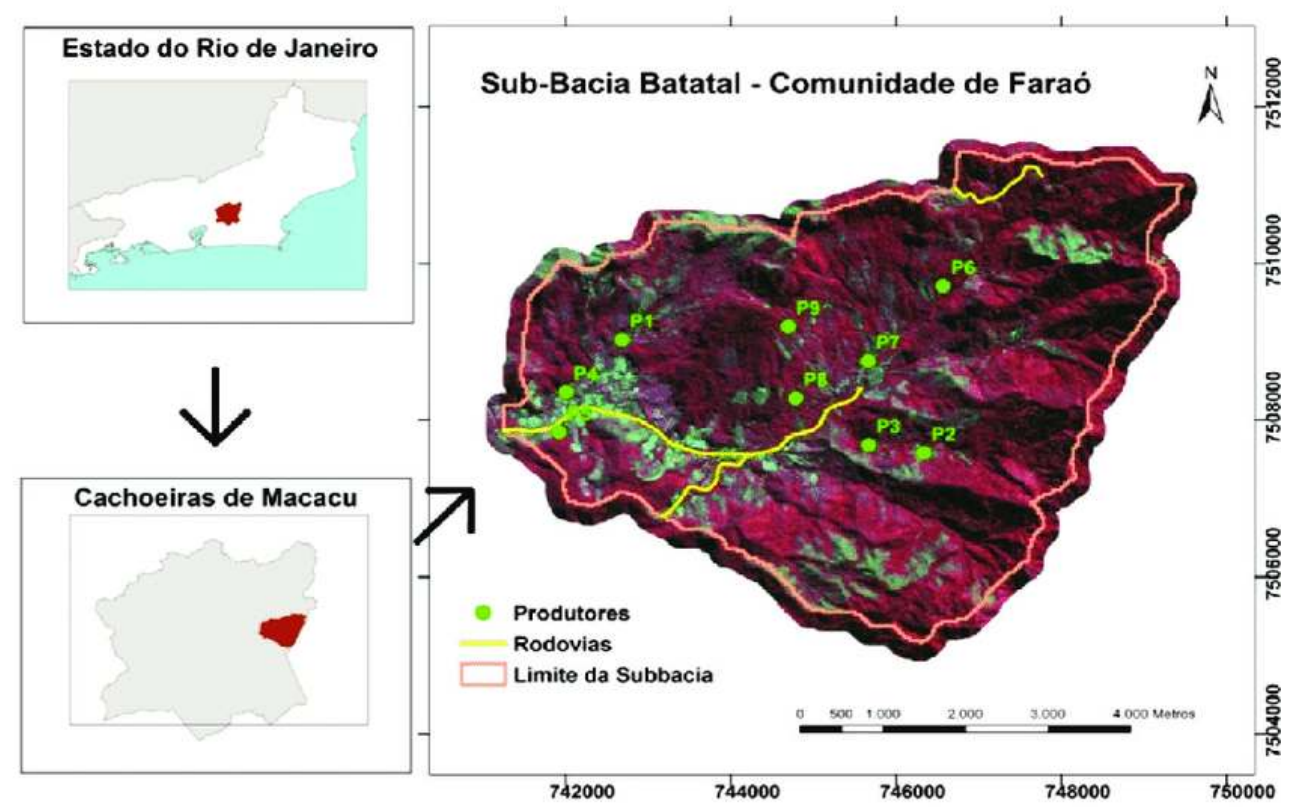

Fonte: Disponível em https://www.researchgate.net/figure/Imagem-1-Ilustracao-do-mapa-da-Subbacia-Batatal-Comunidade-Farao-e-os-pontos-de_fig1_291343912, acessado em 29/04/2019.

10 Constatamos a existência de um grande número de ocupações irregulares na faixa marginal dos cursos fluviais, principalmente no balneário do Baixo Faraó, fazendo com que as margens do rio fiquem ameaçadas pela falta de saneamento básico e pelo desmatamento, prejudicando a fauna e flora, além de comprometer a segurança hídrica regional. Estes eventos prejudicam a economia tradicional e contribuem para a redução da qualidade de vida da população que vive em função do cultivo dos produtos agrícolas locais.

11 As ocupações irregulares foram estimuladas pela exploração de atividades ligadas ao turismo predatório realizadas em períodos de verão e em finais de semana de temperatura elevada elas populações que vivem no entorno e em municípios vizinhos, sem nenhum tipo de controle das entidades municipais de meio ambiente ou de planejamento urbano. Este fenômeno espacial é prejudicial à qualidade hídrica do rio Faraó impactando negativamente a médio e longo prazo a economia local dependente da atividade do balneário.

Concordamos ainda com as observações de Cavalin e Monteiro (CAVALIN \& MONTEIRO, 2012), mostrando que o cultivo da banana é realizado principalmente nas encostas íngremes, sem curvas de nível (Imagem 6), situada predominantemente no Alto Faraó, contribuindo para o desmatamento e elevando o risco de deslizamentos e escorregamentos de sedimentos ocasionados por grandes quantidade pluviométricas pontuais, além de contribuir para a perda de biodiversidade, agravada pela caça predatória e comércio ilegal de animais aumentando o número de espécies em extinção e com proliferação de queimadas nos fragmentos florestais e invasão de espécies exóticas de peixes e moluscos nos cursos fluviais originários de países africanos. Ainda, constatamos o uso inadequado de agrotóxicos nos sítios e áreas de propriedades de especuladores imobiliários destinados a construção de haras e expansão de pastagens para equinos e aumento das tensões envolvendo camponeses e funcionários do Parque 
Estadual dos Três Picos, em relação ao uso da terra na área de amortecimento da unidade de preservação ambiental, observamos, ainda, a extração de areia provocando alterações nos cursos fluviais, verificamos na Imagem 5, uma amostra da perda de comercialização da banana na primeira década do século XXI.

Um grave problema social que tem consequências na estagnação da economia local é a presença de uma juventude rural ociosa, que engrossa as estatísticas de trabalhadores em condições de desemprego, subemprego ou desalentados com o incremento das taxas de desocupação do setor agrícola. Esta desocupação tem por consequências o incremento do êxodo rural para os núcleos urbanos próximos como as cidades de Niterói, São Gonçalo e Rio de Janeiro, principalmente da juventude rural ociosa.

Imagem 5, Tabela 1

Tabela 1. Produção da banana (t) em Cachoeiras de Macacu, RJ - Abastecimento da unidade Grande Rio CEASA/RJ, de 2001 a 2010.

\begin{tabular}{ccccccccccc}
\hline Cultura & 2001 & 2002 & 2003 & 2004 & 2005 & 2006 & 2007 & 2008 & 2009 & 2010 \\
\hline $\begin{array}{c}\text { Banana } \\
\text { 'Figo' }\end{array}$ & - & 0 & - & 1 & - & 8 & 35 & 9 & 4 & 0 \\
Banana \\
'Maçă'
\end{tabular}

Fonte: (CAVALIN \& MONTEIRO, 2012) 
Imagem 6, Foto de área de cultivo da banana sem curvas de nível no Faraó

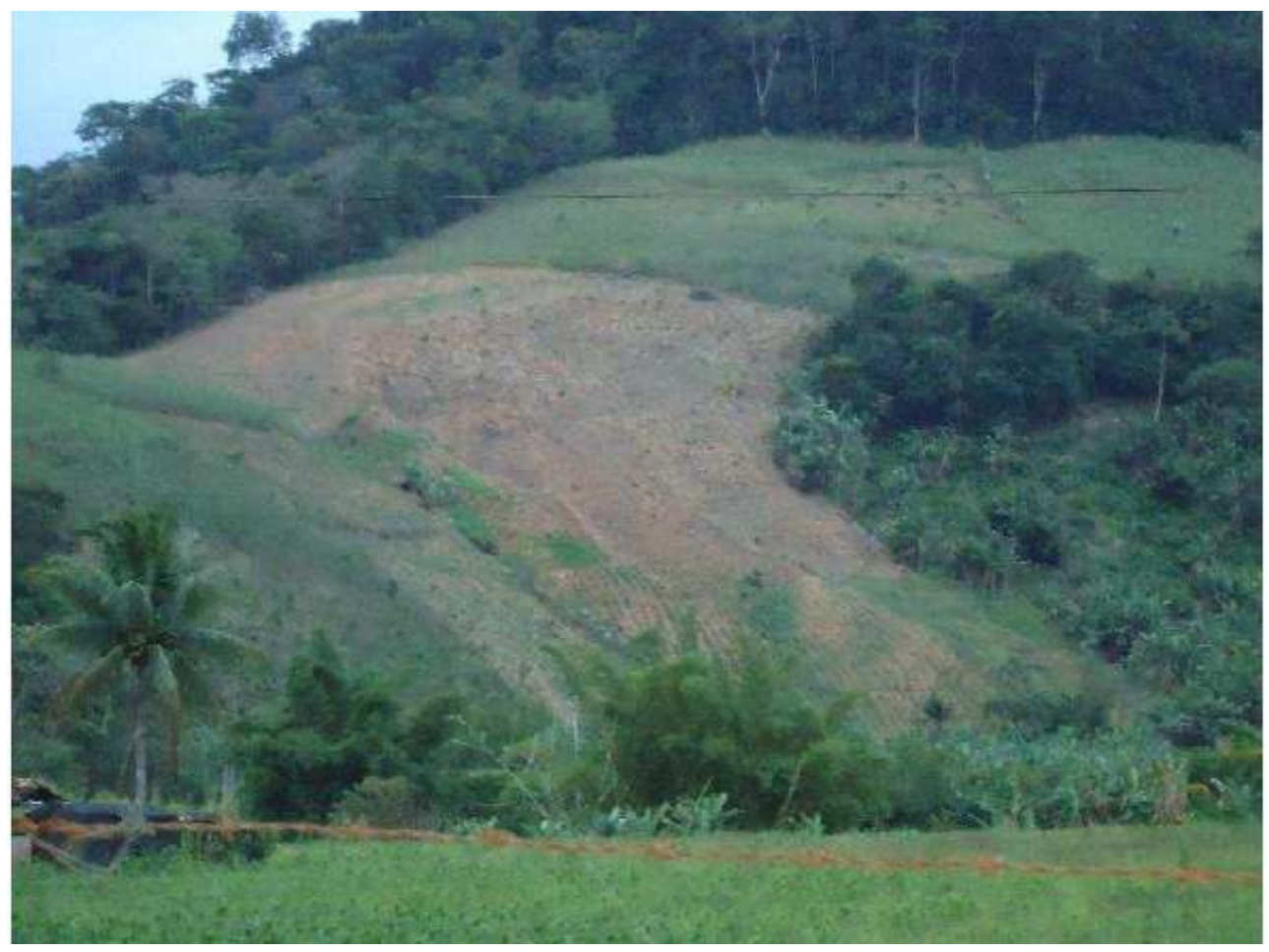

Fonte: (CAVALIN \& MONTEIRO, 2012).

Observamos, também, a invisibilidade do sobretrabalho feminino, fenômeno típico das comunidades camponesas, proporcionando a redução renda da mulher, em relação ao trabalho masculino, que geralmente se apropria dos produtos mais rentáveis da atividade agrícola, provocando impactos decorrentes da desestruturação do núcleo familiar, na medida em que esse procedimento contribui para o êxodo rural, pois um grande número de mulheres, acreditam que podem encontrar melhores condições de trabalho na cidade, pressionando a família para a saída do campo.

\section{Recorte Teórico}

15 Nas observações dos trabalhos de campo, constatamos a presença de articulações entre a comunidade tradicional do Faraó e atores envolvidos na construção do Complexo Petroquímico do Estado do Rio de Janeiro, COMPERJ (Imagem 1), no município fluminense de Itaboraí confirmando as contribuições teóricas de autores como Dollfus, (DOLLFUS, 1972), Santos (SANTOS, 1997), Soja (SOJA ,1993), Lefebvre (LEFEBVRE 1991, 1999) e Bauman (BAUMAN, 1999), que apontaram para a terminalidade ou transformações do segmento em função do avanço da industrialização e da urbanização do campo, retirando o campesinato da terra e transformando-os em proletários rurais ou urbanos, impactando os principais centros urbanos como Itaboraí, Niterói, São Gonçalo e Rio de Janeiro e os municípios no entorno como Cachoeiras de Macacu, Maricá, Guapimirim e Magé como também outros municípios distantes como Duque de Caxias e Nova Iguaçu, caracterizando impactos meso regionais. Conforme Lefebvre (LEFEBVRE 1991) revela: "Sem possibilidade de contestação, esse processo [de industrialização] é, há um século e meio, o motor das 
transformações na sociedade" (LEFEBVRE 1991, p. 11). Em outro trecho o autor também contribui com a discussão:

Nos países industriais, a velha exploração do campo circundante pela cidade, centro de acumulação do capital, cede lugar a formas mais sutis de dominação e de exploração, tornando-se a cidade um centro de decisão e aparentemente de associação. Seja o que for, a cidade em expansão ataca o campo, corrói-o, dissolve-o. (LEFEBVRE, 1991, p.68).

16 Assim, fundamentados nas recomendações de Machado (MACHADO, 2013), Cavalin e Monteiro (CAVALIN \& MONTEIRO, 2010), Fidalgo (FIDALGO et al, 2008) e Trindade Netto (TRINDADE NETO, 2006) sobre as possibilidades do fortalecimento de comunidades tradicionais elaboramos como objetivos específicos desta pesquisa a realização de ações de fomento e formativas ancoradas em práticas agroecológicas e agroflorestais, biomonitoramento dos recursos hídricos, equidade de gênero, mobilização da juventude rural e expansão do turismo ecológico e comunitário, mitigando a exclusão social e econômica da comunidade tradicional do Faraó.

17 A comunidade encontra-se relativamente isolada em relação a outras áreas rurais do município, com o acesso limitado a uma estrada de terra, em precário estado de conservação. $\mathrm{O}$ isolamento, embora possa contribuir para a preservação de características identitárias territoriais (HAESBAERT, 2004), reforçando laços de parentela e afetividade, típicos do campesinato e observadas nas relações da comunidade tradicional do Faraó, acarreta dificuldades para o desenvolvimento local, bloqueando o funcionamento do sistema de trocas, responsável pelo intercâmbio, complementaridade e estabelecimento de redes de inovação (SANTOS, 1997), justificando as ações de ampliação e aperfeiçoamento dos canais de comercialização da produção rural local.

Acrescentamos observações do projeto de pesquisa da EMBRAPA Solos "Macroprograma 6 Construção do Conhecimento para o Desenvolvimento Rural Sustentável: Estudo dos Sistemas de Produção da Comunidade de Faraó, Município de Cachoeiras de Macacu no Estado do Rio de Janeiro" (MARTINS et al, 2016) que esclarece algumas características sociais e econômicas da bananicultura praticada na localidade do Faraó. Neste sentido, destacamos a seguinte contribuição de Martins (MARTINS et al, 2016, pp.17-18) :

O município de Cachoeiras de Macacu, RJ, produz $2.750 \mathrm{t}$ de banana, numa área colhida de $270 \mathrm{ha}$, com produtividade média de $10,1 \mathrm{~kg} / \mathrm{ha}$, superior ao estado (6,2 $\mathrm{kg} / \mathrm{ha}$ ) e próximo à média nacional, que é de $14,5 \mathrm{~kg} / \mathrm{ha}$ (IBGE, 2014). Na comunidade de Faraó, foram identificados dois padrões característicos de sistemas de produção da banana. O primeiro, que constitui a maior parte das áreas produtivas (90\%), é herança de cultivos praticados há 50 anos ou mais. Predominantemente, esse sistema é adotado por produtores com idade de 60 anos ou mais, os quais usam uma escassa mão de obra familiar, recursos restritos, práticas de manejo não especializadas, quase extrativista, sem adubos ou fertilizantes, com pouca ou quase nenhuma tecnologia. Esses produtores preservam o ambiente natural, principalmente nas áreas de encosta e de relevos acidentados. Em alguns casos, mantêm os bananais em sistemas de agrofloresta, muito mais pelas limitações impostas pela influência do Parque ou mesmo por pressão dos órgãos ambientais (MARTINS, 2016, pp 17-18).

\section{Metodologia}

19 A elaboração da metodologia utilizada na pesquisa foi realizada através de alguns procedimentos elencados para dar maior suporte empírico à nossa pesquisa, estudados 
detalhadamente através de autores que trouxeram importante contribuição teórica metodológica. Enfatizamos, contudo que a operacionalização destes procedimentos metodológicos é nosso ponto de partida para as incursões no campo de trabalho sem descartarmos possíveis e bem vindas revisões bibliográficas e conclusões imprevistas de acordo com o progresso das investigações.

Assim, o trabalho de campo exploratório é imprescindível para apurar a atual situação social, ambiental e econômica da população, traçando estratégias conjuntas para resolução de conflitos, vulnerabilidades e potencialidades da comunidade do Faraó. Planejamos que essa atividade seja feita através de entrevistas abertas com os atores envolvidos no recorte territorial delimitado. Nesta etapa empírica, contamos também com observações participantes e abrimos a oportunidade de trabalhar com técnicas de cartografia social, que colaborou para o mapeamento do recorte físico da pesquisa permitindo melhor entendimento da realidade a ser retratada.

21 Também observamos o monitoramento dos serviços ecossistêmicos de polinização e de controle biológico realizado em áreas convencionais e no interior do Parque Estadual dos Três Picos, avaliadas através de métodos participativos (MARCONI \& LAKATOS, 2008) e acadêmicos com a geração de conhecimento e sensibilização das comunidades. Quanto a contribuição do monitoramento dos serviços ecossistêmicos, trazemos a contribuição de Kosmus (KOSMUS, M. et al, 2015):

Reconhecer a correlação entre serviços ecossistêmicos e objetivos de desenvolvimento pode significar a diferença entre uma estratégia de desenvolvimento bem ou mal sucedida, por conta de consequências não examinadas sobre os serviços ecossistêmicos. Uma melhor capacidade de avaliar, descrever e valorar os benefícios dos serviços ecossistêmicos pode ajudar os tomadores de decisão a compreender como suas ações dependem desses serviços e podem melhorá-los. Além disso, os ajudam a considerar os trade-offs entre as opções, e a escolher políticas que apoiem esses serviços (KOSMUS et al ,2015).

Utilizamos também a fundamentação empírica e teórica das informações disponíveis e revisão da literatura pertinente analisando autores como Singer (SINGER, 1973) que ressalta as deseconomias de escala decorrentes dos processos de industrialização e urbanização nas áreas metropolitanas; Correia (CORREIA, 1992) que destaca as estratégias espaciais utilizadas pelas grandes corporações industriais; Piquet (PIQUET, 2012) que analisa a dimensão regional da cadeia produtiva de petróleo do estado; Binsztok e Monié (BINSZTOK \& MONIÉ, 2012) enfatizando os impactos territoriais e ambientais da implantação do COMPERJ (Imagem 1) e suas repercussões na Região Metropolitana do Rio de Janeiro; Trindade Neto (TRINDADE NETO, 2003) difundindo a experiência de recuperação de áreas degradadas implantadas pela Petrobras, na fazenda Outeirinho, em Carmópolis, estado do Sergipe

No âmbito global, mencionamos o estudo de Ross e Viegas (ROSS \& VIEGAS, 2015), recomendando revisão do conceito de enclave na cadeia produtiva de petróleo, pois, esta configuração espacial pode ser relativizada pelas ações de fortalecimento das redes de fornecedores locais, reduzindo o tradicional isolamento do segmento petrolífero. Trazemos a contribuição de Roos (ROOS, 2013, p.147) que destaca sobre esse isolamento produtivo:

A experiência histórica mostrou que impulso econômico dos recursos naturais, por si só, não garante trajetórias exitosas de desenvolvimento, mas requer esforços sistemáticos no sentido da modernização do setor industrial e de uma melhor inserção no comércio internacional. (...) Pensar que apenas o petróleo resolverá os 
problemas estruturais da economia brasileira seria aceitar a presença de

“maldições" e "doenças" já conhecidas mundialmente. (ROOS, 2013, p.147). estratégias conjuntas que implementem as ações previstas, referenciadas pelas orientações conceituais das contribuições de Gusmão (GUSMÃO, 2009), Marconi Lakatos (MARCONI \& LAKATOS, 2008) e Souza (SOUZA, 2015), que enfatizaram a necessidade de articulação entre o conhecimento científico e o senso comum das práticas sócio-espaciais locais.

\section{Considerações Finais}

Os resultados foram amplamente divulgados e debatidos em seminários e encontros da comunidade acadêmica e contando com o apoio das organizações parceiras. As contribuições serão encaminhadas às instituições responsáveis pelo aperfeiçoamento das políticas públicas locais e dos municípios do entorno do COMPERJ (Imagem 1), ampliadas pelas redes de intercâmbio, para difusão em instituições e comunidades localizadas na Área de Influência Direta de empreendimentos da Petrobras distribuídos pelo país. Assim, a proposta apresente condições de ser replicada em outras comunidades camponesas localizadas na Baixada Fluminense, no Leste Metropolitano e em áreas influenciadas diretamente pelos empreendimentos da Petrobras, que estejam vivenciando transformações sociais, econômicos e ambientais similares. Os estudos para a difusão das ações foram realizados com a participação das instituições parceiras, representadas pela Universidade Federal Fluminense e Empresa Brasileira de Pesquisa Agropecuária (EMBRAPA) contando com a contribuição das respectivas redes técnicas científicas destas organizações dotadas de excelente capilaridade no país e no exterior. O longo período de paralisação das obras do COMPERJ e a indefinição sobre o futuro do empreendimento contribuem para a estagnação e decadência das localidades do entorno do COMPERJ na medida em que se fragmentou o conceito de complexo, originalmente adotado para o empreendimento e substituído pela provável implantação de uma refinaria e de uma unidade de beneficiamento do gás natural oriundo das jazidas do pré-sal da Bacia de Santos e transportado por um gasoduto do município de Maricá. Neste sentido, a significativa redução da amplitude geográfica do COMPERJ, abre espaços para uma retomada das práticas camponesas fundamentadas em procedimentos agroecológicos, 
agroflorestais e de recuperação e preservação de mananciais nas comunidades tradicionais dos municípios localizados no entorno do empreendimento, beneficiadas pela proximidade de grandes mercados consumidores das cidades de Niterói, São Gonçalo e Itaboraí e, também, pela incapacidade dos novos atores industriais em absorver os grandes contingentes de trabalhadores mobilizados para a construção do COMPERJ, que, em condições de vulnerabilidade social permanecem na periferia do empreendimento, aguardando um hipotético reinício das obras em grande escala.

\section{BIBLIOGRAFIA}

BAUMAN, Z., Modernidade e Holocausto.Rio de Janeiro, Jorge Zahar Editora, 1999.

BINSZTOK, J. Petróleo e desenvolvimento regional no Brasil. In: Binsztok,\& Monié (Orgs). Geografia e Geopolítica do petróleo. Manaud X. Rio de Janeiro. 2012.

CAVALIM, M. O. \& MONTEIRO, J.M.G. Boas práticas agrícolas recomendadas para o cultivo de banana na Comunidade do Faraó em Cachoeiras de Macacu, RJ. Boletim de Pesquisa e Desenvolvimento 210. Rio de Janeiro: Embrapa Solos, 2012.

CORRÊA, L. R. Corporação, práticas espaciais e gestão do território. Revista Brasileira de Geografia, no 54. 1992. pp. 115 - 121.

DOLLFUS, O. O Espaço Geográfico. São Paulo. Difel, 1972.

FIDALGO, E. C. C.; THOMPSON, D.; TORRES, F. E. N. de; MENDONÇA, R. N. A, Análise comparativa entre estimativa de perda de solos e ocorrências de erosão: estudo de caso na Bacia Hidrográfica do Rio Guapi-Macacu, RJ, in II Seminário da Rede AgroHidro Impactos da agricultura e das mudanças climáticas nos recursos hídricos, Brasília:EMBRAPA, 2014.

GUSMÃO, P. P., Gestão ambiental do território e capacidade de resposta dos governos locais na área metropolitana do Rio de Janeiro. In: Questões metodológicas e novas temáticas na pesquisa geográfica. Orgs: Bicalho \& Gomes. Rio de Janeiro. Publit. 2009. pp. 163 - 184.

HAESBAERT, R., Precarização, reclusão e “exclusão” territorial. Terra Livre Goiânia Ano 20, v. 2, n. 23 p. 35-52 Jul-Dez/2004.

KOSMUS, M. et al, Integração de Serviços Ecossistêmicos ao Planejamento do Desenvolvimento, Deutsche Gesellschaft für Internationale Zusammenarbeit (GIZ) GmbH:Brasilia, 2015.

LEFEBVRE, H., O direito à cidade. São Paulo: Moraes, 1991

LEFEBVRE, H., A Revolução Urbana. Belo Horizonte: UFMG, 1999

MACHADO, F.S., Agricultura e Reestruturação Espacial na Interface Rural-Urbana: O Exemplo do Município de Cachoeiras de Macacu (RJ), Dissertação do Programa de Pós-Graduação em Geografia da Universidade Federal do Rio de Janeiro. UFRJ:Rio de Janeiro, 2013.

MARCONI, M.A.; LAKATOS, E.M., Técnicas de pesquisa: planejamento e execução de pesquisas, amostragens e técnicas de pesquisas, elaboração, análise e interpretação de dados. São Paulo: Atlas, 2008. 
MARTINS, A.L.S. et al, BANANICULTURA na Comunidade de Faraó: Atualidades e perspectivas, EMBRAPA:Brasilia, 2016.

MERCADANTE. A., As Bases do Novo Desenvolvimentismo no Brasil: análise do Governo Lula (2003-2010) Tese (Doutorado em Economia) - Instituto de Economia, Universidade Estadual de Campinas, Campinas, 2010.

PEDREIRA, B.C.C.G., et al, Áreas Prioritárias para Recuperação na Região da Bacia Hidrográfica do Rio Guapi-Macacu, RJ, in Boletim de Pesquisa e Desenvolvimento 191, EMBRAPA Solos:Rio de Janeiro, 2011.

ROOS, B.C., Economia do Petróleo e Desenvolvimento: estudo exploratório sobre as perspectivas do pré-sal brasileiro, Dissertação de Mestrado, UFRN:Natal, 2013.

ROSS, M. L., VIEGAS, G., A Maldição Do Petróleo, CDG EDITORA:2015.

SANTOS, M. A., Técnica espaço tempo: Globalização e meio técnico-científico- informacional, $3 a$. ed, São Paulo: Hucitec, 1997.

SOJA, E. W., Geografias pós-modernas: A reafirmação do espaço na teoria social crítica. Rio de Janeiro: Jorge Zahar Editor, 1993.

SOUZA, M. L., Os conceitos fundamentais da pesquisa sócio-espacial. 2 ed. Rio de Janeiro: Bertrand Brasil, 2015.

TRINDADE NETO, I.Q., Reintegrando a floresta a natureza humana - Um estudo sobre conservação florestal em consórcio com agricultura e produção de petróleo, Carmópolis/Japaratuba, Sergipe. Dissertação de Mestrado em Desenvolvimento e Meio Ambiente, Programa Regional de Pós Graduação em Desenvolvimento e Meio Ambiente, Universidade Federal de Sergipe, São Cristovão, SE:2003.

WILKINSON, J. et al, Caracterização Socioeconômica das Bacias Hidrográficas dos Rios GuapiMacacu e Caceribu, Rio de Janeiro:Embrapa Solos, 2012.

\section{RESUMOS}

A pesquisa analisa os impactos socioambientais enfrentados pela Comunidade Tradicional do Faraó, em Cachoeiras de Macacu decorrentes da reestruturação espacial promovida pela paralisação do COMPERJ, inviabilizando a economia local e liberando força de trabalho utilizada no apoio ao empreendimento. As famílias na comunidade tiveram o cotidiano e sua permanência alterada por problemas ambientais, sociais e econômicos, com o aumento das tensões envolvendo diversos atores em relação ao uso da terra, constatando articulações entre esses atores em função do avanço da industrialização e da urbanização do campo, transformando-os de campesinato em proletários rurais ou urbanos. Assim, recomendou-se o fortalecimento da comunidade do Faraó, mediante ações de fomento e formativas agroecológicas, agroflorestais e de recuperação os recursos hídricos, estimulando a equidade de gênero e a juventude rural, mediante ações de turismo ecológico e comunitário, mitigando os efeitos da vulnerabilidade social e econômica decorrentes dos impactos da inconclusa construção do COMPERJ.

La recherche analyse les impacts socio-environnementaux de la communauté traditionnelle du Pharaon, dans Cachoeiras de Macacu, en raison de la restructuration spatiale favorisée par l'arrêt de COMPERJ, irréalisable l'économie locale et libérant la main -d'œuvre utilisée pour soutenir l'entreprise. Les familles de la communauté avaient leur vie quotidienne et leur permanence changées par des problèmes environnementaux, sociaux et économiques, avec des tensions 
croissantes impliquant plusieurs acteurs liés à l'utilisation des terres, trouvant des articulations entre eux en raison du progrès de l'industrialisation et de l'urbanisation des campagnes. en les transformant de paysans en prolétaires ruraux ou urbains. Ainsi, le renforcement de la communauté du pharaons a été recommandé, à travers des actions de fomentation et de formation agroécologique, agroforesterie et restauration des ressources de l'eau, stimuler l'équité de genre et la jeunesse rurale, sur actions de tourisme écologique et communautaire, atténuer les effets de la vulnérabilité sociale et économique résultant des impacts de la construction inachevée de COMPERJ.

La investigación analiza los impactos socioambientales enfrentados por la Comunidad Tradicional del Faraón en Cascadas de Macacu que se derivan de la reestructuración espacial promovida por la paralización del COMPERJ, inviabilizando la economía local y liberando fuerza de trabajo utilizada en el apoyo al emprendimiento. Las familias en la comunidad, tuvieron el cotidiano y su permanencia alterada por problemas ambientales, sociales y económicos, con el aumento de las tensiones involucrando a diversos actores en relación al uso de la tierra, constatando articulaciones entre esos actores en función del avance de la industrialización y de la urbanización del mismo, campo, transformándolos en el campesinado en proletarios rurales o urbanos. Así, se recomienda el fortalecimiento de la comunidad del Faraón, mediante acciones de fomento y formativas agroecológicas, agroforestales y de recuperación de los recursos hídricos, estimulando la equidad de género, la juventud rural mediante acciones de turismo ecológico y comunitario, mitigando los efectos de la vulnerabilidad social y económica derivadas de los impactos de la inconclusa construcción del COMPERJ.

The research analyzes the social and environmental impacts faced by the Traditional Community of the Pharaoh in Cachoeiras de Macacu resulting from the spatial restructuring promoted by the COMPERJ paralysis, rendering the local economy unfeasible and releasing the work force used to support the enterprise. The families in the community had their daily lives and their permanence changed by environmental, social and economic problems, with increasing tensions involving different actors in relation to land use, noting links between these actors as a result of the progress of industrialization and urbanization. the peasantry into rural or urban proletarians. Thus, it is recommended the strengthening of the community of the Pharaoh, through agro - ecological and agroforestry promotion and training, agroforestry and recovery of water resources, stimulating gender equity, rural youth through ecological and community tourism actions, mitigating the effects of vulnerability social and economic consequences of the unfinished construction of COMPERJ.

\section{ÍNDICE}

Mots-clés: Cachoeiras de Macacu, Pharaon, Baie de Guanabara, COMPERJ

Palavras-chave: Cachoeiras de Macacu, Faraó, Baía de Guanabara, COMPERJ.

Keywords: Cachoeiras de Macacu, Pharaoh, Bay of Guanabara, COMPERJ.

Palabras claves: Cachoeiras de Macacu, Faraón, Bahía de Guanabara, COMPERJ. 


\section{AUTORES}

\section{BRUNO MILAN CARNEIRO DE ALBUQUERQUE}

Universidade Federal Fluminense, Programa de Pós Graduação em Geografia, Pesquisador Associado ao Núcleo de Pesquisas Agroambientais (NEPAM)/CNPq. Email:

geobrunoalbuquerque@gmail.com

\section{JACOB BINSZTOK}

Universidade Federal Fluminense, Docente do Programa de Pós Graduação em Geografia -

Coordenador do Núcleo de Pesquisas Agroambientais (NEPAM)/CNPq - Bolsista de Produtividade do CNPq - Nível 2 - Email: jacob.binsztok@gmail.com. 